\title{
DESIGNING ORGANIZATIONAL STRUCTURE IN THE AGE OF DIGITIZATION
}

\author{
Karlheinz Schwer \\ University of Economics Prague, Czech Republic \\ Christian Hitz \\ University of Economics Prague, Czech Republic
}

\begin{abstract}
The digital transformation will bring about extreme changes, as at the time when the steam engine was invented. To generate money from the emerging opportunities, companies must adapt very quickly. For this, agile forms of organization such as Holacracy are needed where the employees take over the management functions. Is the classic hierarchy still needed in companies?

The following is a brief overview of traditional organizational forms. On the basis of this, the digital innovation capability of hierarchical organizations is analysed. Then it is shown how the new form of organization Holacracy works and how to move from a hierarchical organization to a holocratic one, to fulfil the need of agility. John P. Kotter replied, the hierarchy must not be replaced. He points out that dynamic network organization forms such as Holacracy are important at the beginning of the company's lifecycle. The hierarchy is better suited for stable market environments.
\end{abstract}

Keywords: Organizational Structure, Age of Digitization, Holocracy, Hierarchy, Digital Network, Digital Innovation.

DOI: http://dx.doi.org/10.15549/jeecar.v5i1.213

\section{INTRODUCTION}

Digitization is an essential part of the way we live, work and conduct business. Our world we live in was faced many dramatic digital changes in recent years. (Xu, 2014, p. 3) Therefore, the digitalization is a hot topic. Websites, sensors, content, mobile devices, apps, social tools, etc. are being combined to create new digital experiences, products and services. These services are changing the way we work, eat, shop, relax, play and even learn. As a result markets are being disrupted. The previous companies will be challenged and some will be defeated. The time windows in which interesting possibilities appear will be shorter than in the past. To have a long-term future it is important to accept the digital challenge. (Cox \& Qualtrough, 2016; Summa, 2016, p. 2; Kotter, 2014, vii) The last time when technology has caused such strong changes in business world was the time of the first machines, the first industrial revolution. (Westerman, Bonnet, \& McAfee, 2014) That is why Erik Brynjolfsson and Andrew McAfee call this time "The Second Machine Age" (Brynjolfsson \& McAfee, 2016, chapter 1).

For this change companies need leadership and the ability to deal with imminent constant 
change. The faster companies adapt, the faster they will be a winner. (Summa, 2016, p. 2) John P. Kotter disclaims that these issues need to be accelerated in a company: innovation, productivity improvement, integration of acquisitions or global operations, any sort of key strategic change, cultural change and profitable growth. The acceleration of these issues is stalled by a limited number of change leaders, silo parochialism, rules and procedures, pressures to make quarterly numbers, complacency or insufficient buy-in. (Kotter, 2014, p. 10) Leading, innovative organizations move ahead of fierce competition. They deal with unprecedented turbulences and with the constant threat of technological changes. They do this all without neglecting short-term results or firing people. (Kotter, 2014, vii)

Organizational environments in the future will have the following features:

1. Increases in the number and effectiveness of information, manufacturing, and transportation technologies,

2. More environmental complexity,

3. Increasing environmental competitiveness. (Bøllingtoft, Håkonsson, Nielsen, Snow, \& Ulhøi, 2009, xi)

Therefore it is not surprising, that there is a strong link between organizational architecture to digital transformation and digital strategies because of the acceleration of everything and the question of the digital boundaries in the digital era. Companies need to build a new type of organizational capital in form of capabilities to master the acceleration and the requirements for the organizational adaption. (Bounfour, 2016, p. 8) Digitization requires organizational liquidity, which supports a change-aware culture that enables an organization to detect subtle shifts and continuously adjust the company. The organizational liquidity requires clear goals, flexible roles, accountability, a "fail better" culture and it must engage everyone in the enterprise. For capitalizing on business moments an approach is needed that brings accountability into the organization and uses the social network. (Olding \& Rozwell, 2014)

This article examines the following questions on the basis of a literature review.

- Main question:

- What impact does digitalization have on the organizational structure of companies?

- Sub questions:

- Is a hierarchical organizational structure still contemporary for "digital" companies?

- What alternative organizational structures are useful for companies in the digital age?

\section{ORGANIZATIONAL ARCHITECTURE - BUNDLING TASKS INTO JOBS AND SUBUNITS}

For designing the organizational architecture for a firm, tasks need to be bundled into jobs. This task is very important because this policy choice can have a huge influence on the productivity of the firm. When we bundle tasks into jobs, we distinguish between specialized task assignment and those with broad task assignment. (Brickley, 2016, p. 432)

\section{PURELY HIERARCHICAL ORGANIZATION}

Jobs can be grouped into subunits based on functional specialty, geography, product, or some combination of the three (Brickley, 2016, p. 432).

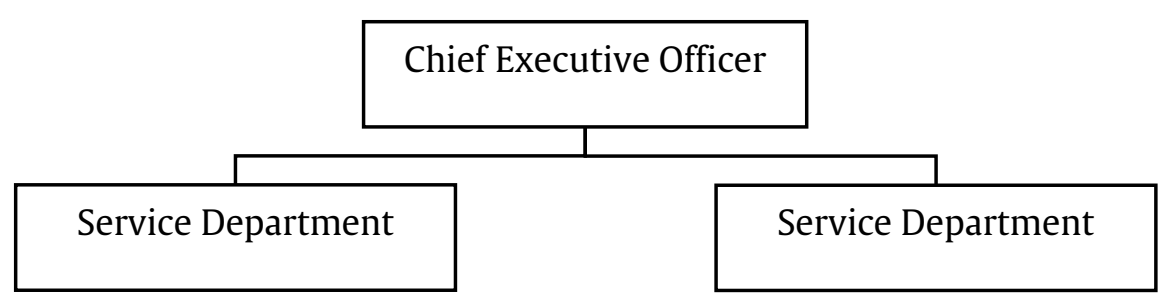

Figure 1. Brickley 2016 - Functional Organization

Source: Brickley, 2016, p. 418

In a functional organization all jobs with the same function are grouped in one department. Advantage of functional organization is that the coordination and the knowledge in relation to a part of the business is bundled in a functional area. The promotion path for employees is well- 
defined. In summary, the problem is that leading, management and coordination within and between departments need a lot of time, is expensive, the risk of coordination failures is high, employees are more focused on their own functional specialty than on the customer. Functional subunits seem to work best in smaller firms where the number of products is limited and the operating environment is stable (Brickley, 2016, pp. 432-433).

\section{ALTERNATIVE ORGANIZATION STRUCTURES}

Larger firms often form subunits based on product geography. In the multidivisional $M$ firm, the operating decisions are decentralized to the business-unit level while the senior management of the firm is responsible for major strategic decisions. A primary benefit of the Mform corporation is, that decision rights for the operational business are dedicated to people lower in the organization. Decentralizing decision rights to business-unit managers gives them incentives to use their specific knowledge productively and frees senior executives to focus on other topics.
Product Organization

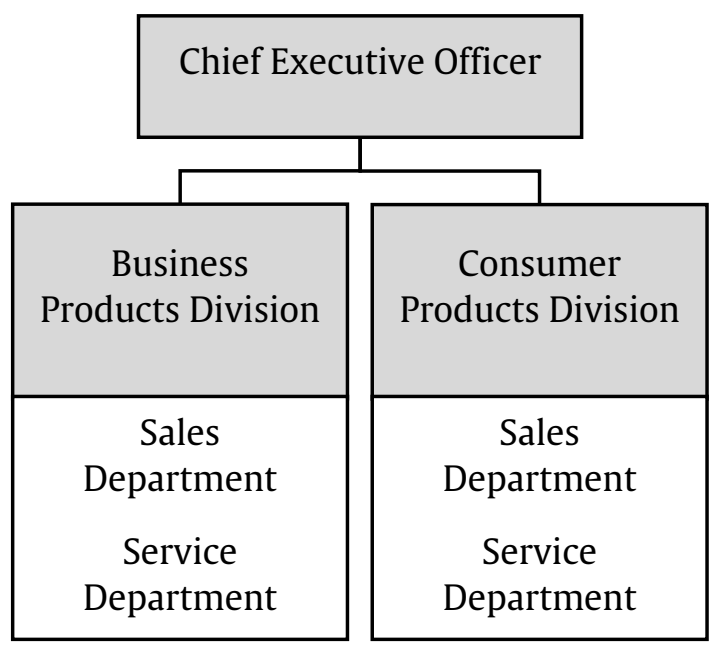

Geographic

Organization

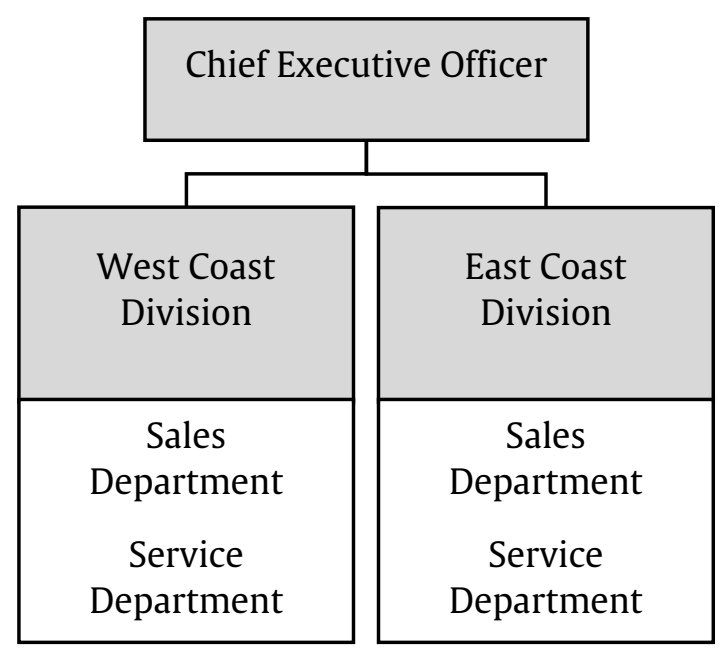

Figure 2. Brickley 2016 - Product and Geographic Organization

Source: Brickley, 2016, p. 419

Problems arise when business-unit managers only consider their departmental objectives and do not pay attention to the success of the company as a whole. The matrix organization is an overlapping structure of functional and product or geographic subunits. The matrix organizational units have functional departments, such as finance and marketing. Example: Team members of a product team must inform a product manager and at the same time a functional supervisor. An advantage, compared to a pure functional organization is that individuals focus more on the superior business process than only on their special function. The advantage compared to a pure product organization is that the functional departments help to increase the business success. The disadvantage of this form of organization is that authorities often cross over
(Brickley, 2016, p. 433).

To organize subunits, companies often use more than one method, this is called mixed designs. One example is that big, multinational companies are organizing the international divisions around a matrix concept (Brickley, 2016, p. 426).

The organizational design has a critical influence on how firms adapt to the business environment. The organization design increases a firm's ability to sense and seize business opportunities by making its organizational boundaries more permeable. (Bøllingtoft et al., 2009, xvi) One example of such a permeable organization form is the network organization. Network organizations consist of work groups based on function, geography, or some other dimension. Specific projects and work activities define the relationships among the work groups 
rather than formal lines of authority. Cooperative undertakings and information flows among work groups can be facilitated by networks. However, dependency on individual agreements and strong informal communication can also lead to misunderstandings (Brickley, 2016, p. 426).

\section{DIGITAL INNOVATION IN HIERARCHIC ORGANIZATIONS}

\section{Too Much Hierarchy Slows Down Decision Making}

Hierarchies are control and decision-making points. They create an environment in which permission must be asked for everything that is not planned and not yet approved. While control instances are desirable, micro management and hierarchical control are not desirable. Too much hierarchy lengthens and slows down the decision-making processes which is not appropriate in an accelerated digitized world. Therefore hierarchy is not a surplus value, it is an obstacle in a digital corporate culture (Summa, 2016, p. 84).

It is important to find the balance between formal decision-making and an agile approach. Hierarchical coordination points such as project applications, examination for strategy conformity, profitability considerations, etc. can very well be a desired hurdle in order to avoid unexpected rapid shots and waste of resources. Also, structures for managing and controlling of digital activities are very useful. The only question is who has the power of decision: only those who are responsible for the line or the employee with the best professional expertise? (Summa, 2016, p. 84).

\section{Structural Acceleration Of Decisions}

From several possibilities, one is the structural acceleration of decisions. The average span of control is the average number of people who report to a manager. The expansion of this number is a way to speed up the decisionmaking process because a fewer number of people have to be involved in decision making processes. As a side effect, the individuals feel more motivated because of their greater selfresponsibility (Summa, 2016, pp. 84-85).

\section{Acceleration Through Increased Attention}

There is a link between CEOs' span of control and the attention span. (Bandiera, Prat, \& Sadun, 2014 , p. 20) Flat hierarchy means not only fewer decision points. The welcome side effect is that fewer direct reports favour the ignoring and delegation of certain topics. CEOs with a broad span of control are investing their time in their own team and in the interacting with their own employees. They often take part in meetings with participants from different disciplines and functions. (Summa, 2016, p. 86) This would mean that executives with a broad control span, are more likely to come into contact with the cross-sectional topic of digitalization. The attention of management is the essential basis for encouraging learning processes at the management level. This in turn is beneficial to make the right decisions. The more direct employees a manager has, the more he interacts interdisciplinary in the meetings, exchanges and shares knowledge. In this way, he favours thought-provoking impulse changes in favour of a digital world and an improvement in digital leadership (Summa, 2016, pp. 86-87).

\section{Acceleration By Increasing The Scope For Decision And Action}

Whether the organizational structure is simple or complex, it is important whether the individual areas of responsibility are given more creative possibilities and whether these are stimulated to self-organization. (Summa, 2016, p. 87).

\section{Startup Agility: From Hierarchy To Holacracy}

Digital start-ups are faster, more agile, and are usually less concerned with corporate organization and internal policy than large, established companies. They are more adaptable and react much faster to changes in the market or customer needs. Leaders dominate over managers, as opposed to large corporations, where managers deal with complexity rather than with change and innovation and where they reluctantly give power to their team. But what if we give up the stabilizing and controlling function of hierarchy in favour of a new organizational structure? How can good ideas become market-ready faster in order to remain competitive? How can we take the "fast lane" if it justifies and requires the situation? (Summa, 2016, p. 117).

A fast lane is Holacracy. Insights from various theories of human development were equally 
relevant to the organizational form of Holacracy, as well as findings from a progressive theory of organization and from quantum physics as well as from cybernetics. (Werther, Jacobs, Brodbeck, Kirchler, \& Woschée, 2014, p. 23) In Holacracy, there are no managerial positions, conventional structures (e.g., hierarchy), and job titles are dispensed with. Management is decentralized and employees are given more selfresponsibility and self-organization. There are no fixed job descriptions, but these are created flexibly depending on the project. Employees are much more motivated and deliver better results. Restrictions on rigid corporate

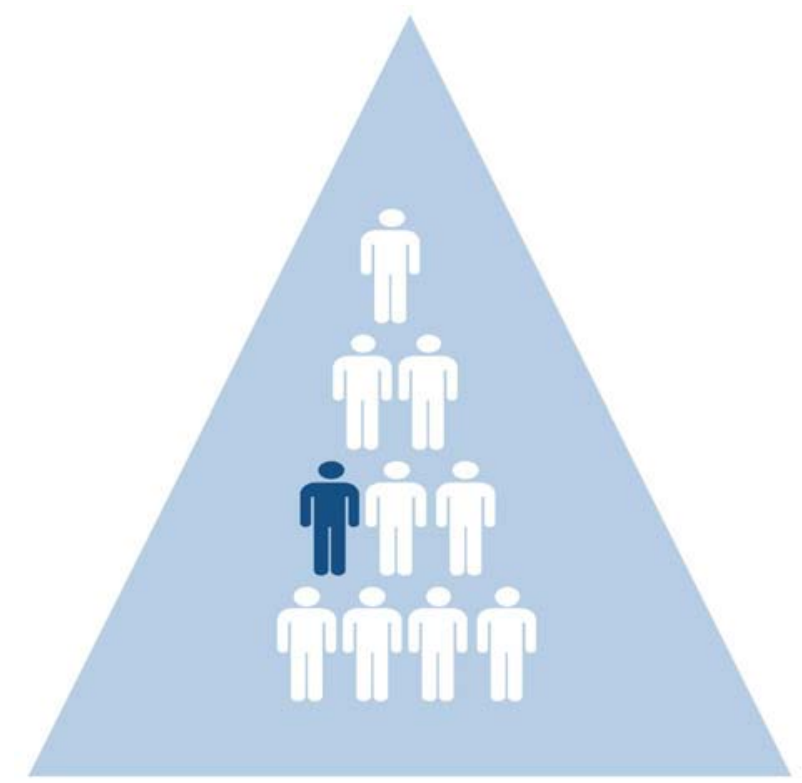

Figure 3. Hierarchy versus Holacracy

Source: Summa, 2016, p. 119

Holacracy includes the following elements:

- a constitution, which redistributes authority,

- a new possibility for structuring an organization and defining the roles and spheres of authority,

- a decision-making process for updating the organization roles and authorities,

- a meeting process for keeping teams aligned and getting the work done (Robertson \& Allen, 2015).

Because Holacracy is an agile method for the organization of the enterprise it is likely to complement with existing Agile approaches in software development (Pepijn van de Kamp, 2014, p. 23). structures are abolished in favor of flexibility as well as improved and faster market adaptability and increased efficiency (Summa, 2016, pp. 117-118). Holacracy is a holistic system to selfmanage the organization. The peer-to-peer "operating system" of Holacracy replaces the traditional management hierarchy. It increases transparency, accountability, and organizational agility. The tested meeting process and transparent rule set, makes it possible to distribute authority, empowering all employees to take a leadership role and make meaningful decisions (HolacracyOne).

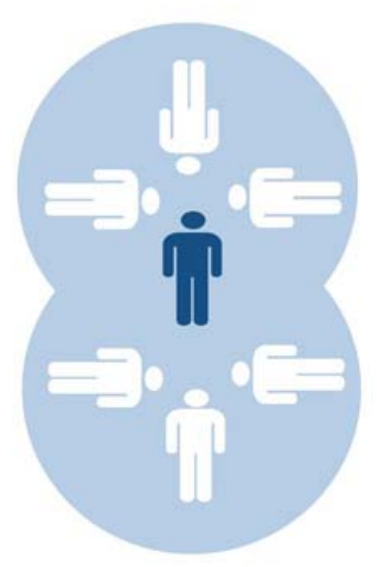

\section{RULES, ROLES AND MEETING STRUCTURE OF HOLACRACY}

Dynamic Roles Replace Static Job Descriptions: In most companies each person has exactly one job description, which very often does not have much to do with the daily work. In Holacracy, employees have more than one role, often on different teams. Within the daily work process, these role descriptions are permanently updated. As a result, the employees have much more freedom to show off their creative talents, thereby improving employee performance. Because roles are not directly related to employees, it is easier for people to hand-off roles and accept new roles than if they were to hand-off or accept new 
tasks within a line organization. (HolacracyOne)

Distributed Authority Replaces Delegated Authority: In traditional organizations the managers decisions beat always those of their employees and unusual initiatives needs the managers approval. The authority in Holacracy is shared over the people. The individual closest to the front line meets the decision. Teams get a purpose, but they are self-organized. They decide within their team how to best fulfill the purpose. The hierarchy is replaced with a series of interconnected but autonomous teams ("circles"). This shift can dramatically increase a company's capacity to adapt to changing conditions. It also allows Holacracy companies having alignment and agency without having "leaderless" groups and autocratic micromanagement that slows everything down, like it often exists in traditional organizations. (HolacracyOne)

Rapid Iterations Replace Big Re-orgs in traditional companies: In traditional companies, there are reorganizations every few years. Through these reorganisations one tries to adapt to the change in time. Because these adjustments occur only every three to five years, they are always out of date. In Holacracy companies the roles and processes are revised in frequent "governance meetings". The organizational structure is updated every month, in every team, in small steps, so very organically. (HolacracyOne)

Transparent rules replace political games: In many companies often it is not clear who, how and why rules have been defined and it is difficult to change existing rules. This makes distributing authority in the organization almost impossible, because there is no way to ensure that everyone is following the same set of rules. In Holacracy, authority is not distributed by a leader at the top down to a group. Authority is defined according to a defined process, defined in a written document, the Holacracy constitution. All people in the company are bound by those same transparent rules. Therefore, it is easy for everyone to see who can make which decisions in the company. (HolacracyOne)

In Holacracy existing different types of meetings: A governance meeting does not address any operational issues. The participants of a circle meet regularly to establish the governance of the circle. These meetings define the general roles, responsibilities and accountability requirements. The roles are assigned to the circle members. All members of a circle can participate in the meeting. Such meetings take place at least once a month. (Robertson, 2007)

In regular operational meetings the daily business is discussed by all members of the circle. The goal and the content is an optimal implementation of the day-to-day business. There are different types of operational meetings that take place at different time intervals, such as daily stand-up meetings and tactical meetings. (Robertson, 2007)

Strategic meetings take place at different intervals depending on the organization. The focus of the strategic meetings is on the broad "big" issues facing the circle. The format of strategic meetings can change, but there should be no more than two topics to be dealt with in a meeting. Special-topic meetings deal with a special topic. These meetings are most likely to be comparable to meetings in typical organizations, and the form of the meeting is defined by the theme (Robertson, 2007).

In a circle there are different key rolls, which must be occupied:

1.a representative connected to the next higher circle (supercircle),

2.a moderator who ensures that the meetings are efficient,

3.a secretary who records the decisions and keeps a list with the roles and accountability of a circle.

The members of the circle elect who will occupy the key roles (Robertson, 2007).

\section{FROM HIERARCHY TO HOLACRACY}

Summarized in Holacracy the traditional pyramid shape is replaced by different circles. Teams are called "circles" and each circle has a partner who is responsible for the fact that people fulfill their roles. An employee can belong to different circles, as opposed to the hierarchical classification. The decision-making process is decentralized, the authority is distributed among individual employees. Responsibilities are clearly defined and employees become more independent, which in turn increases their satisfaction as well as their flexibility (Summa, 2016, p. 118). The following figure shows how Holacracy circles (teams) can be formed from a hierarchical organization: 
The differences between the organization of summarized in the following table: traditional and Holacracy companies are

Table 1. Traditional vs. Holacracy Companies

\begin{tabular}{|c|c|}
\hline In Tradit & With Hol \\
\hline \begin{tabular}{|l} 
Job descriptions \\
- $\quad$ Each person has exactly one job. \\
- $\quad$ Job descriptions are imprecise, rarely \\
updated, and often irrelevant.
\end{tabular} & $\begin{array}{cl}\text { Roles } & \\
\text { - } & \text { Roles are defined around the work, } \\
\text { not people, and are updated regularly. } \\
\text { - People fill several roles. }\end{array}$ \\
\hline $\begin{array}{l}\text { Delegated Authority } \\
\text { - Managers loosely delegate authority. } \\
\text { - Ultimately, their decision always } \\
\text { trumps others. }\end{array}$ & $\begin{array}{l}\text { Distributed Authority } \\
\text { - Authority is truly distributed to teams } \\
\text { and roles. } \\
\text { - } \quad \text { Decisions are made locally. }\end{array}$ \\
\hline $\begin{array}{l}\text { Big Re-Orgs } \\
\text { - The org structure is rarely revisited, } \\
\text { mandated from the top. }\end{array}$ & $\begin{array}{l}\text { Rapid Iterations } \\
\text { - The org structure is regularly updated } \\
\text { via small iterations. } \\
\text { - Every team self-organizes. }\end{array}$ \\
\hline $\begin{array}{l}\text { Office Politics } \\
\text { - Implicit rules slow down change and } \\
\text { favor people "in the know". }\end{array}$ & $\begin{array}{l}\text { Transparent Rules } \\
\text { - Everyone is bound by the same rules, } \\
\text { CEO included. } \\
\text { - Rules are visible to all. }\end{array}$ \\
\hline
\end{tabular}

Source: HolacracyOne

HIERARCHY AND A DIGITAL NETWORK Situation in Big Enterprises

For traditional large companies, it is difficult to abolish the hierarchy organization form and introduce a completely new organizational form such as Holacracy (Summa, 2016, p. 122). Furthermore, John P. Kotter claims that the management-driven hierarchies used by good enterprises are still necessary to make organizations work (Kotter, 2014). There are people who recommend replacing the old organizational structure, designing the organization as a spider web, firing the middle management and managing the workforce themselves. But with a good structured hierarchy and managerial processes the management-driven hierarchical organization can produce incredibly reliable and efficient results on a weekly, quarterly, and annual basis (Kotter, 2015, pp. 6-7).

Executives have always successful carried out initiatives to optimize productivity in their hierarchically managed companies, but now they are trying to innovate even more and even faster. The success of these new initiatives is often elusive. Today it is not unusual that the new initiatives develop very well and then begin to fall apart (Kotter, 2014).

There is a dilemma between short-term and long-term action. On the one hand, day-to-day business and efficiency improvements are to be mastered well. On the other hand, the right thing is to be done in the long term to remain competitive. Internal tayloristic structures do not fit into the digital world. Thus, the hierarchy can be only one dimension of the overall structure. Other structural elements are needed to promote agility, creativity and speed required by the market (Summa, 2016, p. 122).

\section{Organization Life Cycle}

Practically all successful organizations go through a similar life cycle. First they are organized in a network-like structure, like a solar system with a sun, planets, moons and satellites. (Kotter, 2015, p. 6) The "Guiding Coalition" is the sun, the strategic initiatives are the planets and the sub initiatives are the moon. Unlike a hierarchy that seldom changes, the network can change and adapt with ease. 
(Summa, 2016, p. 123) Founders are placed in the center of the system. Others are placed at various nodes working on different initiatives. Individuals are energized and move quickly and with agility. Actions are guided by a vision that people buy into. Energized individuals move quickly and with agility (Kotter, 2015, p. 6). The network is usually very interdisciplinary and independent of the degree of the people, thereby silos and power levels are dissolved. (Summa, 2016, p. 123) Through several steps a structured hierarchical enterprise evolves which is driven by managerial processes: planning, budgeting, job defining, staffing, measuring, problem solving (Kotter, 2015, p. 6).

The network side in a company is invisible in the normal organization lifecycle for most people. This lack of understanding has not cost us much in the past. In the accelerated modern times, however, this is becoming more and more expensive to not understand the duality of organizations with network and hierarchy
(Kotter, 2015, p. 13).

\section{Solution: Kotter's "Dual Operating System"}

The solution is a second system that is organized as a network. On the one hand is a hierarchy and on the other a network. The network imitates successful companies in the entrepreneurial phase. Therefore, there are no organization charts with reporting relationships, formal job descriptions and status levels as in a hierarchical organization. The organizational result is a dual operating system. This makes an existing hierarchical organized enterprise easier to run while accelerating strategic change. The dual system helps to achieve better strategic initiatives in order to take advantage of major opportunities and avoid major risks. It helps not much to manage the company better (Kotter, 2015, pp. 9-10).

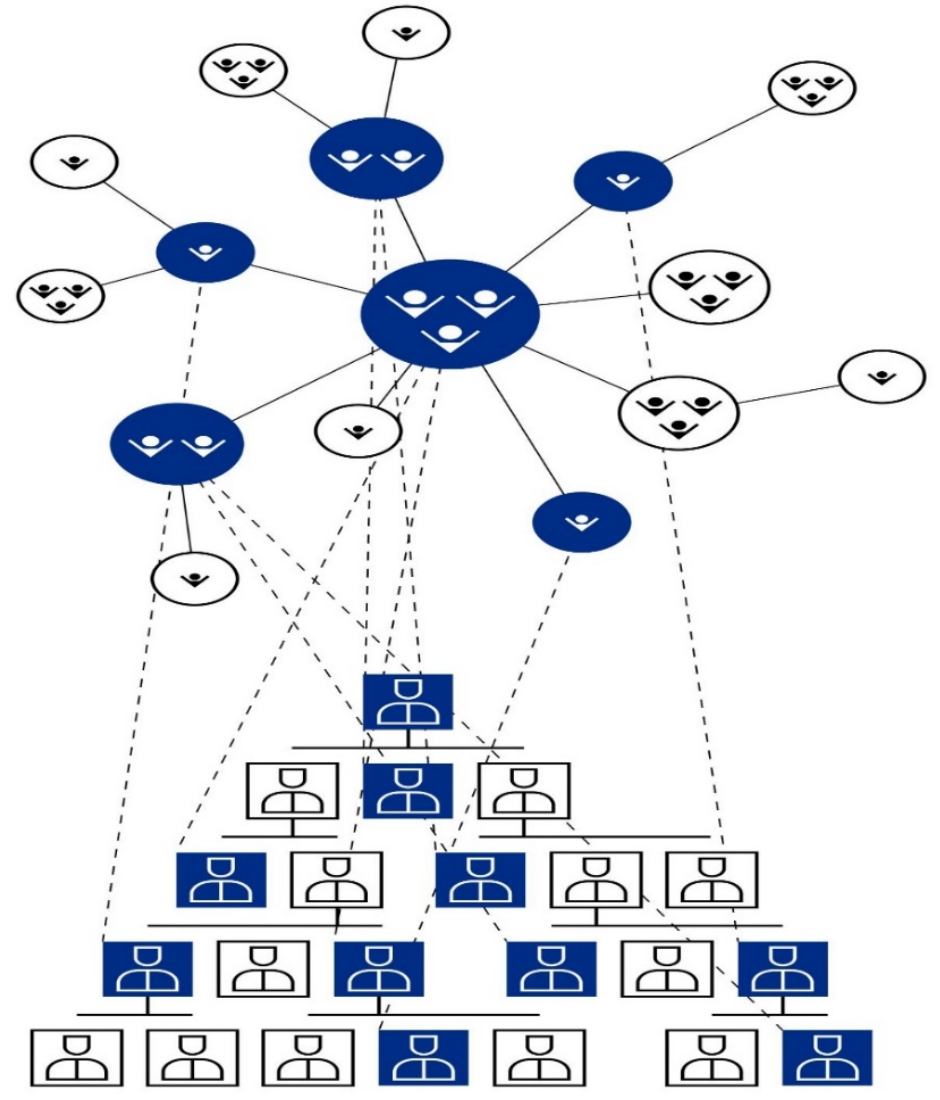

Figure 4. Kotter 2015 - The Dual System

Source: Kotter, 2015, p. 11

The network in the dual system is constantly changing. Because there are no bureaucratic layers, command and control bans or quality management processes, there is room for individuality, creativity and innovation that cannot be created by the best executives in a hierarchical structure. Due to the fact that a wide range of employees are in a network, 
information flows much more freely and faster. (Kotter, 2015, p. 10)

The hierarchy system is relieved in the dual operating system. Initiatives involving innovation, agility, and difficult strategic changes are implemented in the network. As a result, the hierarchical organization is better able to perform daily business, ongoing changes and surprises with a predictable outcome, such as routine IT upgrades. Ideally, the network is intertwined with the hierarchy and is not a detached "super-task force" that reports to some level in hierarchy. However, it is very important that the top management team initiates, promotes and ensures that the hierarchy and the network are aligned with each other. The top management must make it clear that the network is part of a system to win and compete. (Kotter, 2015, pp. 10-13)

A well-functioning dual operating system is guided by these basic principles:

- Many different innovative employees with good working relationships with others driving important changes, not only the few usual employees.

- Leaders and change agents need a "get-to" mind set, not a "have-to" one.

- Actions need to be driven as well by heart, not only by head.

- Not just more management, much more leadership is needed.

- The result should not just be an enhanced hierarchy. The partnership between the hierarchy and the network must be inseparable (Kotter, 2015, pp. 13-15).

The processes in the network organization are similar to the activities of successful entrepreneurial situations. There are eight accelerators defined for the network:

1.Among as many people as possible it should be generated a sense of the urgency associated with great opportunities. People should think about the contribution they can make to the opportunity every day.

2.Building and evolve a Guiding Coalition of people from all silos and levels who have the ability and want to help to take on strategic challenges, deal with hyper competitiveness, and win the Big Opportunity. These people want to lead and change things in the company. In the dynamic network solar system these people will represent the sun.
3. A change vision should be developed and strategic initiatives should be formed that can move you with speed and agility toward the vision. These initiatives should be adopted where the passion of the members of the guiding coalition is the greatest and which are not feasible from the hierarchical organization.

4.A Volunteer army is to be built. This army helps to communicate information about the strategic visions and initiatives in the company to attract many people for the activities.

5. By eliminating barriers, actions are enabled. Everyone on the network side acts like in a fast and entrepreneurial start-up and helps to quickly implement initiatives and find new strategically relevant ones.

6.Short-term wins are to be realized. It is about realizing and celebrating a sustained flow of visible, strategic gains. This helps, for example, to strengthen cooperation and faith in the new structure.

7.Sustain acceleration is to be achieved through the completion of sub-initiatives which do not make a direct substantial and strategic contribution. If such initiatives are not completed, the major initiatives lose their power and support.

8. Institute change helps to institutionalize wins, integrating them into the hierarchies processes, systems, procedures, and behaviour. This helps to infuse the changes into the culture of the organization (Kotter, 2015, p.15).

\section{CONCLUSION}

The changes for people and their enterprises caused by the digital transformation or the second machine age will be as strong as lastly the changes caused by the first industrialization, in the time when the steam engine was invented. Companies need to be able to adapt more quickly to an ever more rapidly changing world in order to make money from business opportunities.

Hierarchically managed line organizations can be made more agile, by expanding the span of control, increased attention, more creative scope and incentives to self-organization. The resulting acceleration of the functioning of the hierarchical organization is not sufficient. Therefore, according to John P. Kotter, the 
hierarchical structure can only be one part of the necessary organization structure for the accelerated world.

A new organizational form to achieve the acceleration needed is Holacracy. At Holacracy, the management is decentralized and employees are given greater scope for selfresponsibility and self-organization. This makes employees feel more motivated and deliver better results.
John P. Kotter notes that the hierarchy can also perform very well in the new accelerated world if the business is already developed or stable. In the phase of the business life cycle, when business is built, it needs an agile structure as it represents Holacracy.

The following table shows a comparison of traditional organization forms with new open organization forms like Holacracy, which are more agile than the traditional ones.

Table 1. Traditional and open organization forms

\begin{tabular}{|l|c|c|c|}
\hline & $\begin{array}{c}\text { Bureaucratic } \\
\text { line } \\
\text { organization }\end{array}$ & $\begin{array}{c}\text { Matrix and project } \\
\text { organization }\end{array}$ & $\begin{array}{c}\text { Open organizational } \\
\text { forms }\end{array}$ \\
\hline Hierarchy & High & Medium & Low \\
\hline Ability to change & Low & Medium & High \\
\hline Centrality & High & Medium & Low \\
\hline Project focus & Low & High & High \\
\hline Complexity & High & Medium & Medium \\
\hline Density of communication & Low & High & High \\
\hline $\begin{array}{l}\text { Self-responsibility of } \\
\text { employees }\end{array}$ & Low & Medium & Medium \\
\hline Transparency & High & Medium & \\
\hline
\end{tabular}

Source: Werther et al., 2014, p. 38

This analysis shows the starting, not the end point of the discussion about new organizational forms. John P. Kotter says the twenty-first century will force us all to evolve toward a fundamentally new form of organization and that the companies that get there first will see immediate and long term success - for shareholders, customers, employees, and themselves. Therefore, companies should now start finding out what is their best organization form for the future.

\section{REFERENCES}

Bandiera, O., Prat, A., \& Sadun, R. (2014). Managing the Family Firm: Evidence from CEOs at Work. Retrieved from www.theigc.org/wpcontent/uploads/2015/02/Bandiera-Et-Al2014-Working-Paper.pdf

Bøllingtoft, A., Håkonsson, D. D., Nielsen, J. F., Snow, C. C., \& Ulhøi, J. (2009). New
Approaches to Organization Design (Vol. 8). Boston, MA: Springer US.

Bounfour, A. (2016). Digital Futures, Digital Transformation: From Lean Production to Acceluction (1st ed. 2016). Progress in IS. Paris, Cham: CIGREF a network for large companies. Retrieved from http://search.ebscohost.com/login.aspx?dire $c t=$ true $\&$ scope $=$ site $\& d b=$ nlebk\&AN=1076509

Brickley, J. A. (2016). Managerial economics and organizational architecture (Sixth edition). The McGraw-Hill series in economics. New York, NY: McGraw-Hill Education.

Brynjolfsson, E., \& McAfee, A. (2016). The second machine age: Work, progress, and prosperity in a time of brilliant technologies (Norton paperback). New York: W. W. Norton \& Company.

Cox, I., \& Qualtrough, E. (2016). Digital uncovered: It takes a lot more than technology to succeed in the digital world. 
[United Kingdom]: Axin.

HolacracyOne, L. L. Holacracy, How It Works. Retrieved from http://www.holacracy.org/how-it-works/

Kotter, J. P. (2014). Accelerate: Building strategic agility for a faster-moving world. Boston, Massachussets: Harvard Business Review Press.

Kotter, J. P. (2015). The Organization of the Future: A New Model for a Faster-Moving World.

Olding, E., \& Rozwell, C. (2014). Organizational Liquidity Readies Enterprises for Digital Business.

Pepijn van de Kamp. (2014). Holacracy - A Radical Approach to Organizational Design.

Robertson, B. J. (2007). Organization at the Leading Edge: Introducing Holacracy ${ }^{\mathrm{TM}}$. Integral Leadership Review, 7(3).

Robertson, B. J., \& Allen, D. (2015). Holacracy: The new management system for a rapidly changing world (First edition). New York: Henry Holt and Company.

Summa, L. (Ed.). (2016). Digitale Führungsintelligenz: "Adapt to win": Wie Führungskräfte sich und ihr Unternehmen fit für die digitale Zukunft machen.

Wiesbaden: Springer Gabler. Retrieved from http://dx.doi.org/10.1007/978-3-65810802-1

Werther, S., Jacobs, C., Brodbeck, F. C., Kirchler, E., \& Woschée, R. (Eds.). (2014).

Organisationsentwicklung - Freude am Change. Berlin, Heidelberg: Springer Berlin Heidelberg.

Westerman, G., Bonnet, D., \& McAfee, A. (2014). Leading digital: Turning technology into business transformation: Harvard Business Press. Retrieved from https://books.google.ch/books?hl=de\&lr=\&id $=$ Fh9eBAAAQBAJ\&oi=fnd\&pg=PR4\&dq=digita $1+$ transformation\&ots=07SlDY5ls9\&sig=R6_E SBgsjQ-VrfVXvt2Tvxn-780

Xu, J. (2014). Managing Digital Enterprise. Paris: Atlantis Press.

\section{ABOUT THE AUTHORS}

Karlheinz Schwer, email: schk08@vse.cz

Mr. Karlheinz Schwer is a PhD student at the University of Economics in Prague. He works as a lecturer and management consultant at the Zurich University of Applied Sciences in Switzerland. Prior to that, he worked as a management consultant on projects in various industries.

Christian Hitz is a PhD student at the University of Economics in Prague. He works as a lecturer and management consultant at the Zurich University of Applied Sciences (ZHAW) in Switzerland. He is also head of the IT Strategy \& Management department at the ZHAW School of Management and Law. Prior to that, he worked as a management consultant on projects in various industries. 